\title{
História Breve do Universo ${ }^{+}$
}

\author{
PROF. JORGE DIAS DE DEUS *
}

Do que eu vou falar é sobre a história breve do universo. É breve porque temos pouco tempo e tentarei falar um pouco sobre tudo, começando pelo nascimento, passando pelo crescimento e terminando no falecimento do dito.

O que é que nós sabemos sobre o começo? Nós, para já, não sabemos muito bem o que é o começo, mas esta transparência (vazia) dános uma ideia: no começo não havia nem espaço, nem tempo, nem matéria. Havia talvez uma singularidadezinha, um pontinho que desenho, que é a singularidade inicial. Essa singularidade inicial é o que se chama o Big Bang (ver Fig. 1). Como vêem, há versões mais ou menos científicas sobre o Big Bang. A grande explosão inicial! Eu tentarei usar aqui a versão mais científica e tentarei explicar porque é que nós acreditamos no Big Bang. Essencialmente há dois argumentos. Um que é o desvio para o vermelho e o outro que é a radiação electromagnética de fundo. Há mais argumentos mas eu vou-me limitar a estes dois.

O primeiro argumento é o do chamado desvio para o vermelho que tem a ver com a observação de radiação dos espectros de luz visível e não visível que vêm das Galáxias. Estas são observações que começaram no final dos anos vinte, em particular por um senhor chamado Hubble que fez observações em 1929 e 1930. Uma galáxia distante emite luz, tal como o Sol emite luz. À volta da Galáxia pode haver certas nuvens, gases, poeiras, que absorvem alguma dessa luz e nós po-

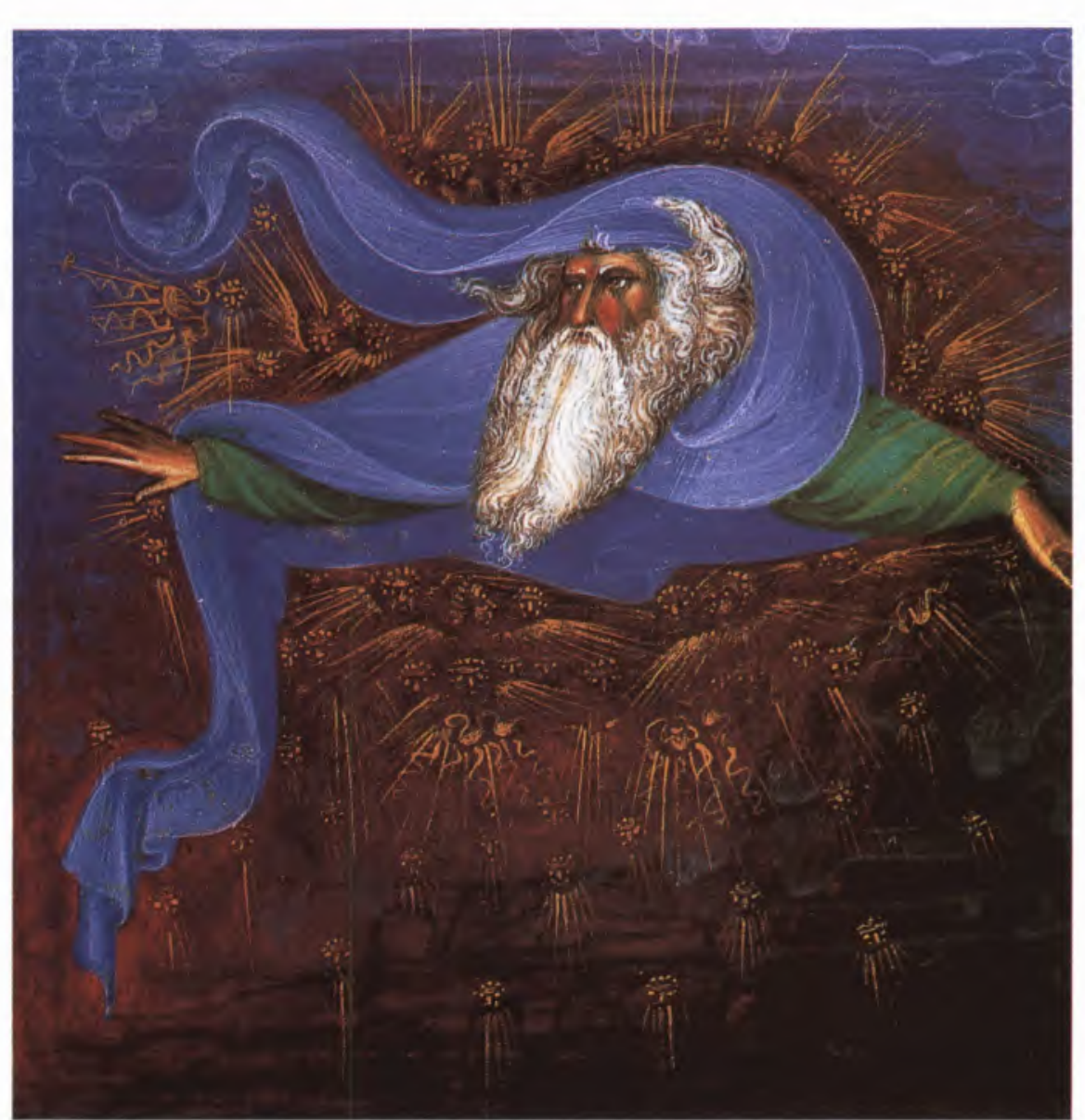

Fig. 1 - Uma visão bỉblica do Big-Bang. ("Biblia d'Este, folio 2v; detalhe da pág. 7. Deus (O criador) disse: "Que haja luz" e a luz surgiu", reproduzido de "Miniatures de la Bibliothèque Vaticane, page. 9) demos estudar essa luz que provém dessa galáxia. Como é que nós a estudamos? Com um aparelho que é essencialmente um prisma. Quando a luz entra pelo orifício decompõese. Há uma parte que é desviada para a zona do azul-violeta e outra que é desviada para a zona do vermelho (ver Fig. 2). A luz com comprimentos de onda maiores é desviada para o vermelho e a luz com comprimentos de onda mais pequenos é desviada para a zona do azulvioleta. O que é que se verifica? O que se verifica quando se vai estudar um espectro de radiação como este é que esse espectro é exactamente o mesmo que se obtém quando se estudam os elementos como o hidrogénio, o hélio... aqui na Terra. Portanto, a primeira conclusão, que é interessante, é a de que encontramos, nas galáxias mais distantes, a mesma matéria e o mesmo tipo de elementos químicos. Cada elemento químico tem um espectro, um conjunto de riscas, como um código de barras dum produto de supermercado. O que nós verificamos é que os códigos de barras são exactamente os mesmos. Os elementos que estão nas galáxias distantes são os mesmos que estão aqui na Terra. Isso dá-nos uma certa ideia duma unidade do universo.

O segundo ponto é o de que as riscas estão todas deslocadas para o vermelho, para os comprimentos de onda maiores. Imaginem que tenho um elemento na Terra, e que tenho uma risca algures nesta chapa. Quando estudo a luz que vem da galáxia essa risca aparece desviada. E aparece desviada para os grandes comprimentos de onda. O espectro é o mesmo mas está todo deslocado para grandes comprimentos de onda (ver Fig. 3). Qual é a explicação disso? A explicação mais simples tem a ver com o efeito Doppler e que diz o seguinte: se a fonte que emitir a luz com velocidade $c$ se estiver a afastar com velocidade $v$ medimos um comprimento de onda diferente. Esta fórmula do efeito Doppler, $\lambda^{\prime}=\lambda(1+v / c)$, mostra que o comprimento de onda vem maior se 
1) DESVIO PARA VERMELHO

Slipher 1910-20

Hubble 1929

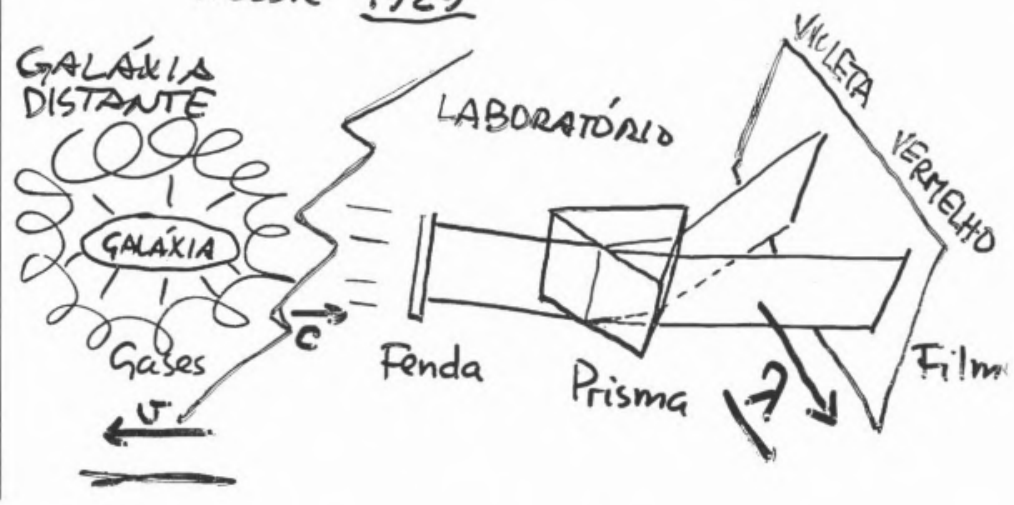

Fig. 2 - A decomposição da luz absorvida vinda das galáxias.

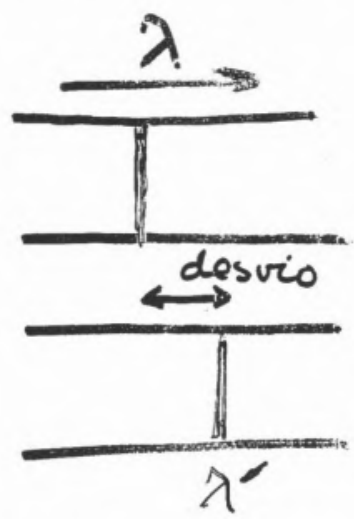

E. mement:

ne Torre.

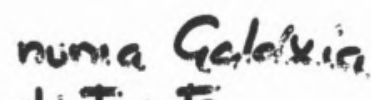
disTanto

Fig. 3 - As riscas do espectro são sempre as mesmas, só que desviadas para a zona dos comprimentos de onda maiores.

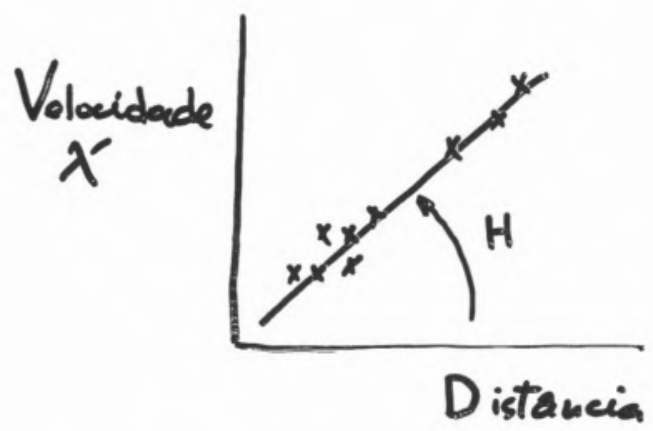

$$
\begin{aligned}
V= & H D \\
& \text { l"constente de Hubsle. }
\end{aligned}
$$

Fig. 4 - A lei de Hubble diz que a velocidade de afastamento das galáxias (V) é directamente proporcional à distância (D) a que se encontram, $\mathrm{V}=\mathrm{HD}$, sendo $\mathrm{H}$ a constante de Hubble. a luz se estiver a afastar: há um desvio para o vermelho. Isto deu-nos a ideia de que, quando se estudam as Galáxias longe de nós, elas estão a afastar-se. O Hubble foi mais rigoroso e estabeleceu a relação quantitativa entre o afastamento das Galáxias e a distância a que elas estão. Evidentemente que nós não medimos a velocidade. Medimos o desvio para o vermelho e interpretamos aquela fórmula anterior. O que o Hubble disse foi que a velocidade (V) de afastamento crescia e era directamente proporcional à distância (D). A relação de proporção é a constante de Hubble $(\mathrm{H})$ muito importante na astrofísica e na cosmologia (ver Fig. 4).

Só uma curiosidade: quando o Hubble fez as suas medições, em 1930, o que realmente tinha era um molho de galáxias, as que se conseguiam observar e as mais perto. Os telescópios não tinham a potência que têm hoje. Ele observou um molhinho de Galáxias e disse que havia uma relação linear. Devo-vos dizer que ele não tinha dados para dizer que a relação era linear. Apenas teve sorte. Depois continuou-se a medir, e só hoje é que se pode dizer que a relação é linear. Mas a prova de que ele não podia estar a medir bem é que ele mediu a constante e esta estava errada por um factor de dez: era 500 e agora é 50 (vezes umas unidades esquisitas que não interessam para aqui).

Enfim, a grande aposta de Hubble foi a de que $\mathrm{V}=\mathrm{H}$. D . Daqui resulta a ideia dum universo em expansão. Vou explicar melhor o que é a ideia dum universo em expansão: quando medimos qualquer coisa temos sempre a ilusão infantil de que estamos no centro do mundo. É evidente que quando olho à volta e digo: Onde está o centro? o centro está em mim. Todos nós somos um centro. Todos temos a mesma noção e se pensarmos em termos de galáxias pensamos que a nossa galáxia é o centro do mundo, quando todas as outras galáxias são igualmente o centro do mundo! Realmente, não há centro 
do mundo. Esta é a ideia do princípio democrático que há em astrofísica. Imaginem que eu estou aqui a fazer a minha observação, e, num dado instante, eu meço uma galáxia $\mathrm{A}$ a uma distância e uma galáxia $\mathrm{B}$ a outra distância. O que é que quer dizer a expansão? Quer dizer que, à medida que o tempo passa, as distâncias A e B aumentaram em relação a mim. Aquilo que $\mathrm{A}$ andou é igual à velocidade vezes o tempo que passou. É fácil de ver que o facto de eu ter a constante de Hubble quer dizer que, à medida que o tempo passa, eu vou vendo a mesma figura, mas ampliada. É o que se chama a relação de homotetia (ver Fig. 5). Vocês podem perguntar: O que aconteceria se eu andar para trás? Se eu andar para trás vou vendo figuras cada vez mais pequeninas. Há uma altura em que eu chego a um ponto. Esse é exactamente o ponto que desenhei no início e que é o resultado de eu
Isto, o desvio para o vermelho, é uma das grandes provas da expansão do Universo.

Mas eu disse que havia uma segunda prova, também muito interessante, mais recente (anos sessenta), da radiação Cósmica de fundo: radiação electromagnética que existe por todo o lado. Isto foi descoberto em 1965 pelos senhores Penzias e Wilson, que não sabiam nada sobre Astronomia, Astrofísica ou sobre a história do universo; de facto trabalhavam em ondas de rádio, e o que observaram foi que nas antenas que eles tinham recebiam radiação que não tinha um emissor específico. Para recebermos a emissão que vem de Monsanto, por exemplo, temos de ter a antena voltada para Monsanto. O que eles repararam foi que, virando a antena para onde quer que virassem, ouviam sempre a mesma radiação de fundo. É evidente que pensaram, como bons físicos, que era ruído de

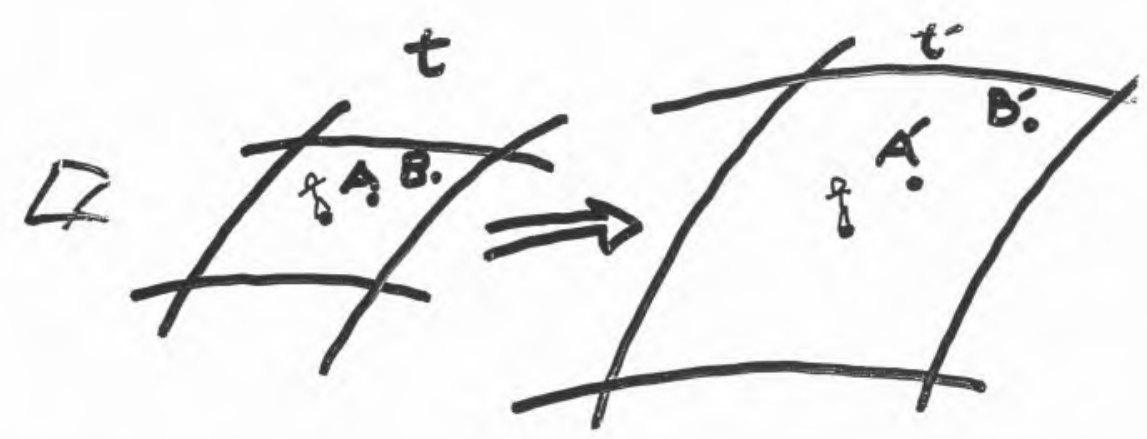

Fig. 5 - O mundo à minha volta no instante $\mathrm{t}^{\prime}$ é uma versão ampliada do mundo visto no instante $\mathbf{t}<\mathrm{t}^{\prime}$. Há uma relação de homotetia que permite calcular o instante inicial em que todo o Universo se encontra num ponto: $t_{U} \equiv 1 / H$.

ter observado que as galáxias se estão a afastar, e que quanto mais longe estão mais rapidamente se afastam, o que me leva à relação de homotetia. Assim, chego à conclusão de que o tempo de existência do Universo é exactamente $1 / \mathrm{H}$. Quando meço $\mathrm{H}$ da linha do gráfico de há pouco, eu sei estimar a idade do Universo. Nós definimos a altura da singularidade inicial e estamos a assistir à expansão do universo. fundo do aparelho e não da própria radiação. Passaram dias, meses, anos a tentar corrigir, até que se convenceram que havia uma radiação de fundo por toda a parte. Como se o nosso Universo estivesse mergulhado nessa radiação. E essa radiação vem de toda a parte duma forma mais ou menos isotrópica.

$\mathrm{O}$ que eles mediram foi a intensidade da radiação em função do comprimento de onda. A partir dos primeiros pontos experimentais deles, em 1965, concluiu-se que essa radiação era de Corpo Negro. O Universo era como que um forno, em que havia radiação emitida lá dentro. A radiação do Sol é também de corpo negro. Essa radiação está ligada à temperatura. Se eu estiver muito frio, essa radiação está nas frequências muito baixas, se estiver mais quente a radiação vai aumentando de frequência. A parte interessante é a de que, a partir destes dados, e se interpretarmos isto como a radiação dum corpo, como se o Universo fosse um corpo, a uma dada temperatura, a radiar, como um radiador eléctrico de resistência, que à medida que vai aquecendo vai mudando de cor (há uma relação entre a cor e a temperatura), e usando esta lei, verificamos que temos uma temperatura de 3 graus Kelvin, que é a temperatura de fundo. Penzias e Wilson verificaram ainda que a radiação provinha de todos o lados, o que vem reforçar a ideia que o nosso universo é muito democrático, é igual para todos o lados e não estamos em nenhum local privilegiado. Eu torno a insistir: Havia apenas três pontos no gráfico. É um pouco como a história do Hubble: deduziu-se que a curva havia de ser esta. Para vos convencer da verdade do que lhes estou a dizer, vou-lhes mostrar os dados de 1989 do satélite Cobe (ver Fig. 6).

É espectacular o acordo dos pontos experimentais de agora, que cobrem tudo. A temperatura, de facto, não é $3 \mathrm{~K}$ mas $\operatorname{sim} 2,735 \pm 0.06 \mathrm{~K}$. Assim, a ideia que temos de que o Universo é isotrópico e que radia como um corpo negro está bastante firme, e isto corresponde à tal singularidade inicial que se vai expandindo, a uma certa temperatura, e que esta temperatura vai baixando. Mas eu já volto a falar nisso.

Só uma curiosidade, que aproveito para contar já: nós podemos medir, através destas curvas experimentais, a densidade de radiação no Universo. Ou, se quiserem, para quem sabe, é a densidade de fotões. $\mathrm{O}$ Einstein disse que as ondas elec- 

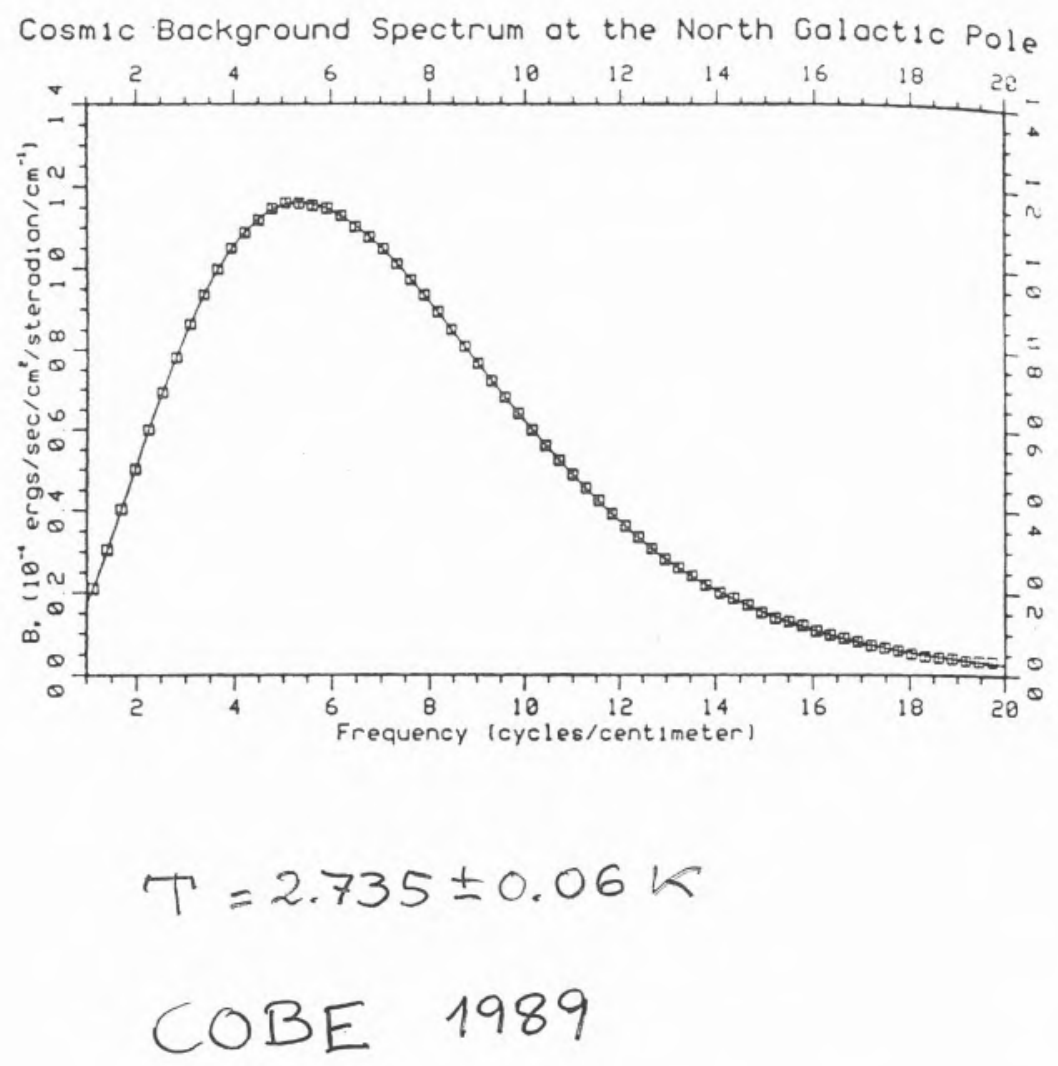

Fig. 6 - O espectro contínuo da radiação electromagnética de fundo, medido pelo detector COBE (1989), em perfeito acordo com a curva teórica, para um corpo a radiar à temperatura de $2,735 \pm 0,06 \mathrm{~K}$.

tromagnéticas têm fotões, e eu posso contar quantos fotões há e obtenho um número. Eis o número de fotões por litro no universo: 550000. Posso também contar matéria: protões, neutrões, pessoas, árvores, galáxias, estrelas... coisas mais para o pesado. Se contarmos esse tipo de matéria, o número que dá é dez levantado a menos três, por litro. Assim, o Universo está muito cheio de radiação e tem pouca matéria. Se quiserem, a quantidade de ondas de radiação de fundo por quantidade de matéria é um factor entre dez levantado a nove e dez levantado a dez. Isto é um dos mistérios da criação: porque é que há tanta radiação e tão pouca matéria. Eu devo-lhes dizer que este mistério seria mais simples se não houvesse matéria nenhuma. Pois se não houvesse matéria nenhuma nós percebería- mos o que se passou. Sempre que há matéria e anti-matéria existe uma tendência para a matéria e a antimatéria se aniquilarem e produzirem radiação. Quando tenho uma temperatura muito alta isto tanto pode ir num sentido como no outro: quem sabe química sabe que as reacções podem ocorrer para a direita ou para a esquerda, mas depende da energia à disposição. Se houver energia que chegue, isso tanto vai para um lado como para o outro, mas o que acontece é que com o universo em expansão, a temperatura baixa e a reacção dá-se num só sentido. Portanto, o que é que quer dizer eu ter tanta radiação?

Imaginem que isto é um protão (p) e isto um anti-protão $(\bar{p})$.

$$
p+\bar{p} \underset{\leftarrow}{\leftarrow} \gamma .
$$

Eles todos se foram aniquilando. Por cada 10 levantado a nove protões ou unidades de matéria sobra-me 1 protão que não foi aniquilado. Portanto, no fim, eu tenho dez levantado a nove mais radiação do que protões, ou dez levantado a nove mais fotões do que protões. Portanto, o grande mistério não é porque é que há tão pouca matéria, mas sim porque é que a quantidade de matéria não é mesmo zero, ou seja porque é que o universo não é simétrico e não se aniquilou tudo? Sabem qual a consequência? Nesse caso só haveria radiação e fotões e não haveriam protões, nem neutrões, nem matéria, nem Terra, nem planetas, nem astros, nem galáxias. Não haveria nada. Nós existimos graças ao pequeno nada que ficou. A Vida é feita de pequenos nadas, como diz Sérgio Godinho...

Voltemos ao nosso fio da meada, que é a ideia de andar para trás no tempo na expansão: as distâncias, medidas em comprimentos de onda, vão diminuindo; as temperaturas vão subir, numa relação que tem a ver com o inverso do comprimento de onda; a energia (energia do corpo negro) vai subir com $\mathrm{T}$ levantado à quarta potência. A conclusão inevitável, segundo a informação que temos hoje, é a de que no início tenho um universo muito concentrado, com as distâncias a tender para zero. É um Universo muito denso, a energia tende para infinito, tal como a temperatura tende para infinito.

\section{A LUTA DA ORDEM CONTRA A DESORDEM...}

Fig. 7 - Toda a história do Universo se traduz na luta entre as forças de ligação (da ordem) e a agitação térmica (desordem). 
Portanto a ideia que tenho é a de que quando este Universo muito concentrado se começa a expandir, a temperatura vai baixando. A radiação com a temperatura de $3 \mathrm{~K}$ é o que resta da radiação a temperaturas extremamente elevadas, um fóssil do que resta do período inicial. O que é que acontece à medida que vou andando para trás no tempo? (ver Fig. 7). A temperatura vai aumentando. Reparem agora na relação entre as temperaturas e as energias de ligação: como sabem existem estruturas, como a molécula, porque existem energias de ligação que asseguram que a molécula seja tal como ela é. O que acontece se puser a molécula ao lume? Começo a ter um jogo entre a ligação que quer manter os átomos todos juntinhos e a temperatura que quer separar os átomos. À medida que ando para trás no tempo vou tendo esta luta entre a ordem e a desordem. A temperaturas baixas a ordem domina e a temperaturas altas tenho a agitação térmica que não deixa as coisas estarem bem ordenadas. É como ter um exército, em que a baixas temperaturas tenho os soldados muito bem alinhados, mas se tiverem passado pela tasca e bebido uns copos, o exército deixa de estar bem ordenado. Se quiserem, outro exemplo simples: considerem uma substância magnética, paramagnética ou ferro-magnética, em que existem uns spins dentro da substância, e existe um campo magnético exterior, que tende a alinhar os spins pela mesma ordem. Se a temperatura for muito alta ganha a desordem. Se a temperatura for baixa, e abaixo duma certa temperatura crítica, tenho uma certa estrutura.

Quais são as forças e energias que nos interessam? Vou falar só de três, embora os físicos digam que existem quatro. A pequenas escalas o que domina é a força nuclear forte. É o que tem a ver com as estruturas dos núcleos, o que tem a ver com os protões, neutrões e as trocas entre estes. Tem a ver com estabilidade em toda a física nuclear.

A médias escalas tenho o domínio da força electromagnética. A quí- mica e a biologia são todas controladas pela força electromagnética. A física da matéria condensada, os átomos e moléculas, a electrónica, etc, têm a ver com esta força.

A grandes escalas, como nós sabemos, domina a força gravitacional. O que mantém a Terra a girar à volta do Sol é a força gravitacional, o que explica as estruturas das galáxias, etc, é a força gravitacional.

Estas são as forças da ordem. Se quiserem ter a noção de como isto actua, teremos este resumo de tudo. Vejam o universo, e comecemos a baixar de escala (fazer zoom): vemos a nossa galáxia, depois o sistema solar, num cantinho fora do seu centro, depois a terra, pintada a azul por causa da água. Olhando para a água vemos as moléculas de $\mathrm{H}_{2} \mathrm{O}$, e continuando a olhar passamos da molécula ao átomo. Tenho aqui o átomo de Bohr, com o seu núcleo atómico e os electrões a andar à roda. Aqui tenho a escala do átomo: dez levantado a menos oito centímetros. Olhando agora para o electrão, a partícula elementar, vemos que este não mostra estrutura. Ainda não se viu nada lá dentro. Mas se olharmos para o protão ou para o neutrão, que constituem o núcleo do átomo, verificamos que existem lá dentro outras partículas: os quarks. Hoje em dia, para os físicos de partículas, as entidades básicas da matéria são os quarks e os electrões.

Quando andamos para trás no tempo vamos passar para um universo mais pequeno. Hoje em dia o nosso universo é controlado pela gravitação, (em grandes escalas, portanto) mas, à medida que vamos andando para trás no tempo, vamos entrando em zonas que são dominadas por outras interacções, até que chegamos às zonas que são dominadas pelas interacções fortes. É por isso que, hoje em dia, a física de partículas e a astrofísica são muito parecidas. Temos a física dos aceleradores, que olha para objectos cada vez mais pequenos, e temos os telescópios que olham para coisas cada vez maiores, e a ironia é que, devido à existência do Big Bang, o andar para trás no tempo corresponde a passar do infinitamente grande para o infinitamente pequeno.

É por isso que podemos escrever uma história do universo. É possível fazer esta história jogando com a hierarquia das forças e com o jogo entre a ordem e a desordem.

Comecemos pelo fim. Temos as pessoas, as árvores, os planetas, etc. Aqui tenho o domínio da gravitação. Se começo a andar para trás chego a uma altura em que a energia térmica é superior à gravitação. Não é possível fazer estruturas, porque a agitação térmica leva-me a que eu não consiga formar estruturas em grande escala. Andando mais para trás começo a ter átomos e moléculas, e ainda mais para trás começo a destruir os átomos e as moléculas. Portanto o jogo é sempre este: tenho estruturas, que a partir de certa altura vão sendo destruídas. Aqui tenho a formação dos núcleos atómicos, a chamada nucleossíntese, em que se formam os núcleos de hélio e de hidrogénio, mas se aumentar a temperatura isto desapa-rece. No fim tenho apenas a força de interacção forte: a que existe dentro dos próprios núcleos atómicos. Isto é uma espécie de Química do Universo!

Só para vos dar uma ideia do que nos diz a teoria: coloquemo-nos na época dos primeiros microssegundos depois do instante inicial. A uma temperatura baixa tenho uma organização. Os protões têm uns quarkzinhos dentro e cada protão está separado um do outro. Há uma certa organização. Se a temperatura é muito grande, acima da chamada temperatura de confinamento, os meus quarks libertam-se, e tenho o que se designa por um plasma, com quarks e gluões. É sempre o mesmo tipo de argumento. Tudo nesta sala está organizado desta maneira, em protões, neutrões, etc. Se a temperatura for muito elevada e chegarmos à temperatura do começo do Big Bang, eu tenho o desconfinamento ou desorganização dessa matéria. Isto é uma coisa que não se sabe. Experimentalmente ainda não foi observada. Hoje faz-se, no CERN (mais uma vez a fí- 
sica do muito grande e do muito pequeno encontram-se), aquilo a que se chama o "Little Bang": Fazer colisões tão intensas que, localmente, posso criar regiões de energias tão densas e com temperaturas tão altas que tenho o desconfinamento, ou seja aquelas estruturas desorganizam-se todas e, em vez de protões e neutrões tenho quarks livres, obtendo o plasma de quarks e gluões. Ora isto são cálculos teóricos. A temperaturas muito altas tenho os quarks livres, depois tenho uma certa transição de fase a uma certa temperatura, e depois tenho as partículas normais.

o que é interessante é que tenho uma escala da ordem do dez microssegundos. Para aqueles que leram o livro do Weinberg "Os três primeiros minutos", o que ele conta é que ao fim desses três primeiros minutos deu-se a formação dos átomos e moléculas, portanto a neutralização das cargas eléctricas, e a altura em que ficou livre aquela radiação de fundo. O que eu estou a falar é nos primeiros dez microssegundos. Estou a olhar para muito mais para trás no tempo. Qual a grande diferença em relação ao Weinberg? A diferença é que a radiação de fundo que aparece ao fim dos três primeiros minutos foi detectada, sabemos exactamente que isso existe, e quanto ao plasma, quarks e gluões nós não temos a certeza da sua existência. Falta-nos esse fóssil do começo do universo.

Eu não vos queria falar mais para trás. Quase todos os livros que a Gradiva e outras editoras (não quero fazer publicidade só à Gradiva) produzem falam muito da história do universo e disto de que eu falei. Gostaria de falar de coisas diferentes. Prever o passado é fácil, mas prever o futuro é que é difícil. O que é que podemos dizer?

Como vos disse atrás, se estiver sentado na nossa galáxia estarei a ver as outras galáxias todas a afastarem-se. E quanto mais afastadas estão de mim maior será a velocidade com que se afastam. E depois? Não tenho bem a certeza. Estamos num universo que se vai expandir sempre ou estamos num universo em que as distâncias voltarão a diminuir (ou seja, que se expande e depois encolhe)? Esta é a primeira pergunta, e que tem uma resposta muito fácil. É um problema que todos podem resolver: é o problema de atirar uma pedra ao ar.

Quando se atira uma pedra ao ar é preciso ter duas coisas em conta. A primeira é a energia cinética com que a pedra é lançada, e a outra é a energia potencial: a pedra tem tendência a cair. É o caso normal. Mas se eu quiser colocar um foguetão no espaço ele sobe e não volta. Isto tudo depende da energia cinética, ou seja da velocidade inicial com que eu lanço o foguetão. Existe uma velocidade limite, cerca de $11 \mathrm{~km} / \mathrm{s}$, com a qual, se o foguetão tiver essa velocidade ou uma superior ele sai e não volta. Ele escapa-se à influência da Terra.

Este problema da expansão do Universo tem exactamente as mesmas duas soluções. A expansão corresponde ao foguetão, ou seja, a energia cinética é tal que a expansão vai continuar, mas se a energia cinética não for suficiente ele voltará para trás. Onde é que nós estamos? Esse problema leva a grandes discussões, e o que realmente interessa é a medição da quantidade de matéria no universo. Eu quero saber qual a importância da gravitação. A gravitação depende de quanta massa lá está. Tudo tem a ver com a densidade de matéria no universo. É uma das quantidades mais importantes, que é preciso medir com cuidado.

Hoje em dia a densidade de matéria é pouca, pelo que a maior parte dos astrofísicos acredita que estamos num universo em expansão. Mas, por outro lado, temos a noção de que ainda não medimos a matéria toda no universo. Existe a chamada matéria escura, que é matéria que não é detectada directamente mas que é necessária nos cálculos gravitacionais. Por isso, pode haver uma densidade de matéria muito maior, e a força de gravitação ser maior. Veremos o que acontece num caso ou noutro.

Devo-lhes dizer que é um problema complicado pois se há retorno a temperatura vai aumentar; se não há retorno a temperatura vai continuar a baixar. Por isso, temos uma certa dificuldade em resolver o problema da nossa existência nas condições dum universo em expansão. Aliás quer seja em expansão quer seja em contracção. O problema interessante é saber se a humanidade tem um futuro ou não. Podem imaginar um universo cada vez mais em expansão, em que a temperatura vai baixando cada vez mais. É um bocadinho o problema, famoso no século passado, da morte térmica do universo. O outro caso é o da contracção. Não vejo como poderemos viver num pontinho semelhante ao que desenhei de início. Teremos todos de viver ao molho, pior do que no Técnico.

Sejamos realistas: o primeiro ponto é que é preciso sair da Terra. Não tenham dúvidas nenhumas. Porquê? A Terra é um parasita do Sol. Vivemos na Terra, temos uma estrutura e uma Terra bonita porque o Sol está a fornecer-nos constantemente energia e entropia. Simplesmente o Sol, como qualquer estrela, não dura para sempre. A estabilidade do sol vem dum certo equilíbrio entre a atracção gravitacional e as reacções nucleares, que criam gases com pressões que compensam a gravitação. É o equilíbrio entre a gravitação e essas pressões que mantém a estabilidade do Sol. O Sol, como qualquer estrela, vai desaparecer, e estima-se algo como dez levantado à décima anos como a duração do Sol. Podem pensar: "Bom, ainda falta muito", mas nós temos de resolver problemas complicados, e agora será uma boa altura para se pensar neles.

Primeiro: temos de começar à procura de outros sistemas solares. Acho interessantíssimas todas as descobertas dentro do sistema solar. acerca de Marte, Neptuno, etc, mas para o caso que estou a tratar, a grandes escalas, não nos adianta muito, pois todos dependem do Sol. Temos de sair do nosso sistema Solar. É evidente que isso levanta problemas complicados de transporte. Como sabem, existe uma velocidade limite da luz, e para me deslo- 
car de um objecto para o outro à distância de anos-luz levar-se-á gerações, que se vão renovando pelo caminho para chegar ao fim da viagem.

O outro problema é talvez o mais interessante, e poderá começar a ser desenvolvido, é o recurso a estações orbitais. Ou seja, ir fazendo as grandes viagens a pouco e pouco. A próxima estação a ser lançada vai ser a estação internacional orbital ALFA. Podemos imaginar um futuro em que vamos estar cheios de estações orbitais, de vôos interplanetários. Esse será o passo intermédio. Esta é uma imagem da ALFA (ver Fig. 8).

É um projecto mundial, que mete os EUA, a Europa, as Chinas... Portugal também está metido. Temos prevista uma experiência, o "Alpha magnetic spectrometer", para medir as radiações cósmicas. A estação internacional estará no espaço em 2002. Uma das zonas maiores é onde vão viver os astronautas.

Ora isto é uma primeira solução. Penso que temos de ir para o espaço. Mas temos o problema de ter de sair da Galáxia, e isso é complicado, devi- do às distâncias e ao tempo que demora. O futuro está no espaço, não há grandes dúvidas, e o problema que se põe, penso eu, é muito parecido com o que se pôs no século quinze. Eis a Terra, com o centro da Europa, Portugal, e o problema que se punha era o de colonizar o espaço que havia. Nós agora temos um problema parecido. Estamos aqui no centro, e temos um universo todo que não está colonizado (ver Fig. 9).

De modo algum temos informação como tínhamos do Marco Pólo, e do Prestes João, mas temos a informação dos telescópios, etc., mas a exploração do espaço é algo que está por fazer.

Uma questão que se pode pôr é o que é que vamos encontrar. Aí as opiniões dividem-se. Há os que acham que há só uma única humanidade inteligente, que é a nossa (partimos do princípio de que a nossa é inteligente...); há outros que acham que existem outras humanidades, outros seres inteligentes. Por exemplo, existe uma pintura muito célebre de Miguel Ângelo, da Cria-

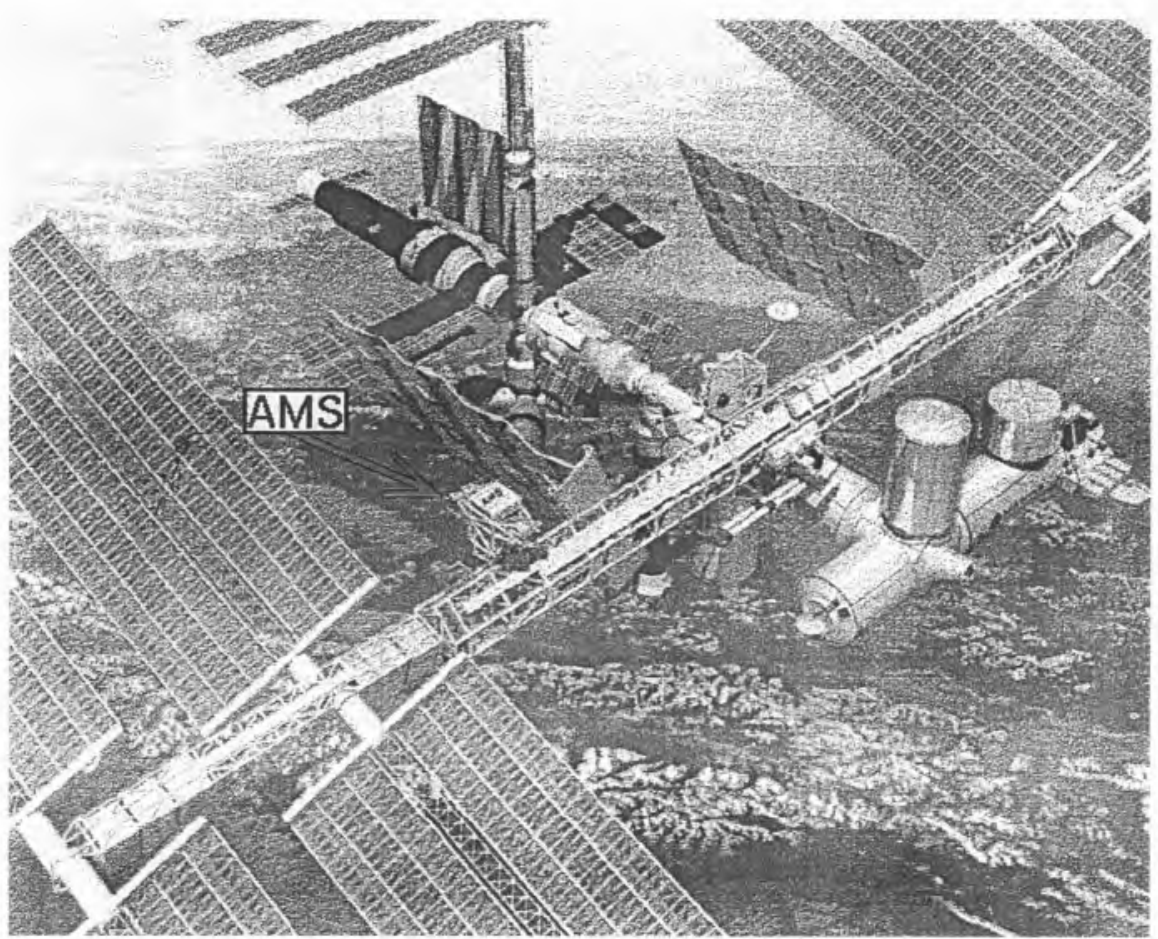

Fig. 8 - Visão futurista da Estação Orbital Internacional ALFA, com o detector de raios cósmicos AMS.
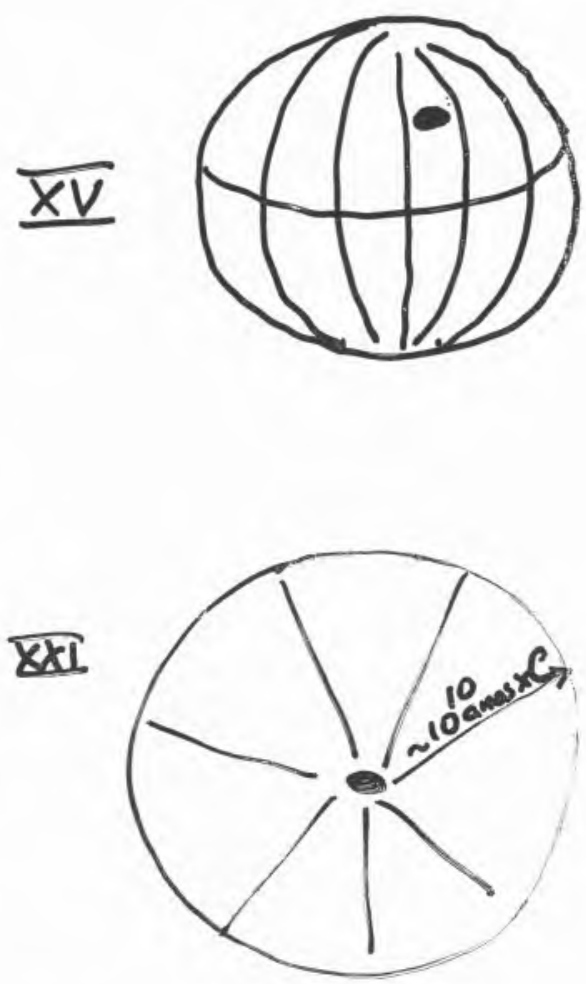

Fig. 9 - A colonização do Universo ou a analogia entre os séculos XV e XXI.

ção, que podemos imaginar como o de uma humanidade mais inteligente a estabelecer o contacto com uma humanidade menos inteligente. Esta é a minha pequena homenagem ao Carl Sagan (ver Fig. 10).

Portanto, temos de sair para o espaço. Iremos encontrar outras humanidades? Pessoalmente não sei. Acho mais interessante que não haja, pois é um problema mais interessante de resolver. Outro problema: Sobretudo no caso do universo em expansão. Confesso que se o Universo se retrair não sei como resolver o problema da vivência num fogareirinho, o ponto inicial. Mas creio que, duma maneira ou de outra, nós precisamos de criar novas formas de vida. Somos seres que vivem a trinta e seis graus, com estruturas extremamente complexas: carne, ossos, dentes... somos seres energeticamente muito desfavorecidos. Do ponto de vista Darwinista, não estamos preparados para viver 


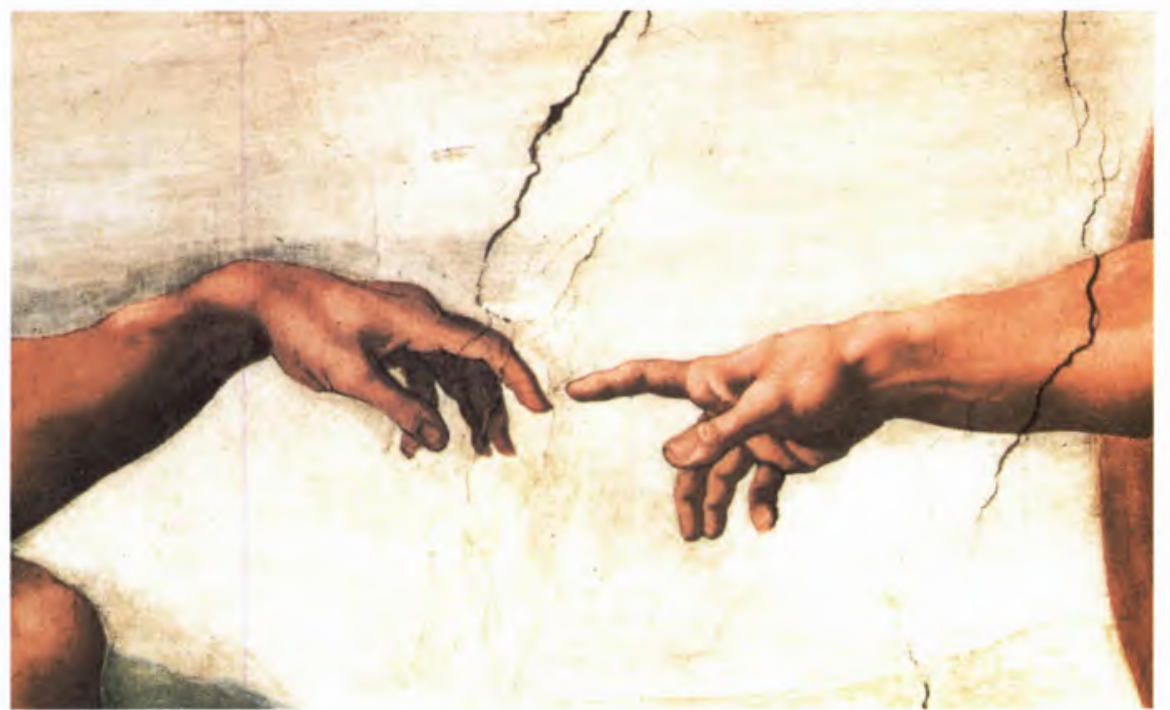

Fig. 10 - Contacto...

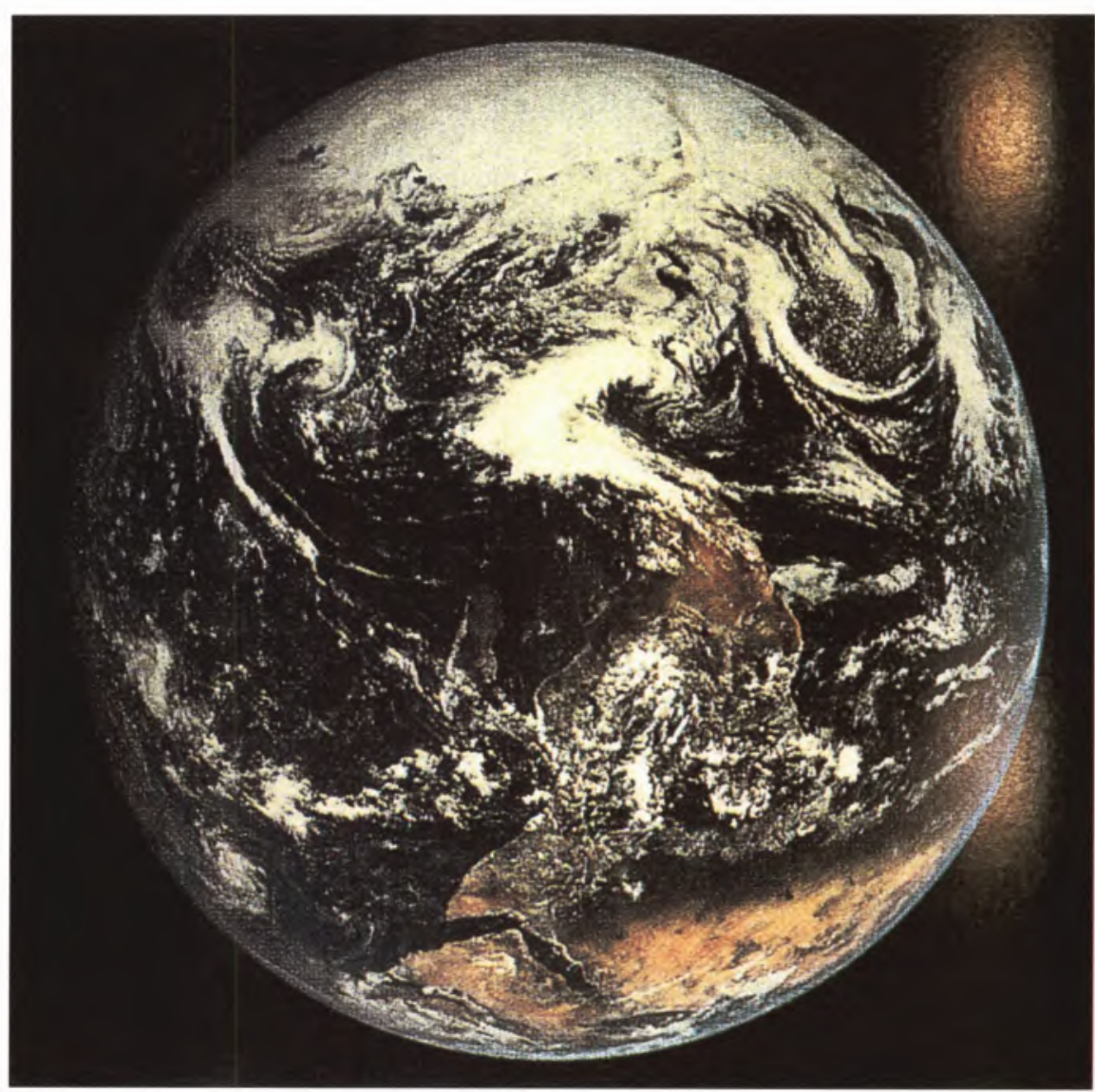

Fig. 11 - Esta Terra que vos deixo... num universo em expansão. Temos de criar novas formas de vida que não exijam temperaturas tão altas nem estruturas tão complexas.

Sem querer ofender os químicos e biólogos presentes na assistência, a definição de vida pode não ter nada a ver com a química nem com a biologia que conhecemos, pois na definição de vida entra no essencial a capacidade de se adaptar, de se reproduzir, de assimilar. A forma como nós a conhecemos é com base na química, nas macromoléculas, no DNA, mas realmente a definição de vida não precisa disso. Posso dar uma definição formal de vida, e posso imaginar outras vidas formadas com electrões e neutrinos, por exemplo. Não me peçam um modelo, pois não sou capaz de o dar, mas podemos imaginar outro tipo de estruturas que não tenham problemas com a temperatura, que não tenham ossos para partir, que não tenham carne pesada, etc. Existe esse outro tipo de problemas, mas temos tempo para pensar neles: dez levantado a vinte anos.

Assim, o que há para realizar: a saída do sistema solar, para o qual precisaremos dez levantado a dez anos; a criação de novas formas de vida; mas talvez o mais importante seja preservar aquilo que temos. Sem isso não poderemos ir mais longe. Já agora quero lembrar-vos o que é a Terra: eis a Terra, versão da NASA (Fig. 11). Terra que é o nosso ponto de partida, mas que não será o nosso barco final. Mais tarde ou mais cedo teremos de mudar de barco, mas para já temos de o manter. Espero que estas imagens finais levem a pensar e a imaginar que temos certos limites, e, por outro lado, que temos de ter os pés assentes na Terra. E este é um problema para já. Dez levantado a zero anos...

* Departamento de Física - IST

+ Esta Conferência foi proferida na sede da SPQ integrada no Ciclo de Conferências organizado pela Divisão de Educação no ano lectivo de 1997/1998. O texto foi elaborado a partir de uma transcrição publicada no Pulsar, jornal da licenciatura de Engenharia Física Tecnológica, IST. 